\title{
Analysis of Rural Surplus Labor Migration under Institutional Economics Perspective
}

\author{
Lin Han \\ Liaocheng Vocational and Technical College, Liaocheng, 252000, China
}

Keywords: Rural, Surplus labor force migration, Institutional economics

\begin{abstract}
Rural surplus labor migration mainly means labor force gets rid of traditional agricultural activities and enters the secondary industry and the tertiary industry. This not just directly influences issues of agriculture, but also concerns development course of industrialization and urbanization and affects social fairness. This paper sets forth comparative income in the process of Chinese rural surplus labor migration, analyzes current situation of rural surplus labor migration and proposes countermeasures to accelerate rural surplus labor migration course under institutional economics.
\end{abstract}

\section{Introduction}

Since China implemented rural reform at the end of 1970s, agricultural productivity has developed rapidly, thus leading to rural surplus labor force and surplus labor force migration has appeared. As China transits to market economy from planned economy, labor mobility range also continues to expand. Under regulation and control of market, labor force mobility can not just achieve optimized combination of labor resources, but also drive transformation of economic system. In recent years, as China's industrialization process speeds up, increasing rural labor force starts to enter large and medium-sized cities. Thus, larger-scale surplus rural labor migration appears. With China's rural surplus labor migration, some negative effects will occur inevitably during accelerating economic development. Thus, rural surplus labor migration under the new situation is also faced with some difficulties. Here, the author adopts the method of institutional economics for discussions.

\section{Comparative income in the process of rural surplus labor migration}

As China's rural household contract responsibility system is carried out, lack of incentive mechanism in microcosmic operation is solved at the bottom. However, under the relationship pattern where urban and rural areas fail to achieve integration, income of vast mass peasants cannot rise by the increase in agricultural production. In recent years, the proportion of disposable income of urban population in net income of peasant households boosts continuously. Thus, comparative income gained from agricultural production is still greatly lower than urban employment efficiency. Labor resources of rural areas are also transported to cities. Considering diversified agricultural operation and absorption capacity of township enterprises for surplus rural labor force drop, it is necessary to achieve rapid economic growth through reform, and make peasants find out job opportunities in non-agricultural industries through trans-regional mobility. Thus, the largest-scale labor resource flow tide in the history forms.

Because China reduces agricultural product price control force, a very large price difference forms between the rapid rise in agricultural input cost and grain price. Besides, since 1980s and 1990s, the proportion of national input in rural areas in finance is on the decrease. However, Chinese peasants who start to get rid of institutional restriction still continue to seek the opportunities to give play to production potential and improve household income so that traditional urban-rural relationship pattern practically changes at a fast speed. The major driving force of such change is large-scale rural labor force migration and trans-regional flow. In this way, urban-rural labor force market integration is achieved. In addition, new labor resource allocation is realized in an increasingly large range.

This policy adjustment which promotes rural labor force to realize regional flow is mainly the result of interaction or game of several subjects. This interaction mainly occurs among labor force 
outflow place, inflow place, government, local and central governments, low and local urban labor force. Generally, in policy adjustment process, reform is also listed in the factors to promote economic development which should be considered preferentially. Besides, the principle of Pareto improvement serves as the basis. Although peasant workers suffer some unfair discriminations in wage and welfare, their income limit is on the rise. Although migrant workers may embezzle welfare of urban citizens and affect local employment posts, some local governments change attitude to some migrant workers. However, in general, each local government is still tolerant to labor force entrance. Meanwhile, participation in urban construction by peasant workers fills up the gap of cities in urgent need of numerous posts. Their contributions to local economy and society are also prominent.

\section{Current situations of rural surplus labor migration}

Firstly, current land system greatly hinders rural labor force from migrating and flowing to cities. In recent years, most peasants engaged in non-agricultural industries complete labor force migration through informal channels. Under current system, the peasants who have achieved migration through informal channels lack implementation of rational economic compensation for those who transfer or give up land contract use right due to institutional imperfection. Thus, they will keep owning land ownership in rural areas and thus labor force breaking away from the secondary and the tertiary industry select part-time operation.

Secondly, population urbanization course is quite slow. Based on analysis of modern national development course, urbanization development and industrialization development keep pace. This is an inexorable trend for traditional industrial structure to upgrade and also one of important symbols of Chinese economy modernization. Meanwhile, it is also a fundamental countermeasure to shrink the gap between urban and rural areas, eliminate dualistic economic structure, accelerate rural labor force migration, improve income of mass peasants and properly solve issues of agriculture. Currently internationally recognized index to judge urbanization refers to the proportion of urban people in total population in China. Chinese urbanization develops rapidly in large and medium cities as well as eastern region, while it develops quite slowly in underdeveloped regions and especially central and western regions.

Thirdly, existing surplus rural labor force is difficult to adapt the requirement of non-agricultural industries for comprehensive quality. At present, among nearly 500 million of rural labor forces, rural population with the education degree of senior high school or above only accounts for $12 \%$, and rural population with the education degree of junior college or above only accounts for $2.6 \%$, while rural population with the education degree of junior high school and below is as high as $88 \%$. On the whole, rural labor force in China is characterized by low education degree and lack of skills in non-agricultural industries. With economic development of Chinese coastal region in recent years, labor-intensive type transforms to capital-intensive type and technology-intensive type. Since employment in non-agricultural industries has increasing high requirements for workers' quality, employees need to transform from original strength type to skill type. For those rural workers lacking solid technology, their competition strength in employment market becomes increasingly weak, and employment space also becomes smaller and smaller.

The above various factors will certainly have the direct bearing on surplus rural labor migration speed and scale. This is mainly due to policy implementation result under guidance of structuralism development view. Thus, it is urgently necessary to form rural surplus labor migration countermeasures under guidance of institutional economics which comply with current actual needs.

\section{Countermeasures to accelerate rural surplus labor migration under guidance of institutional economics}

To boost marginal productivity of agricultural industry

The fundamental strategy to relieve agricultural labor force migration is till to improve marginal productivity of agricultural industry. Nowadays, excessive migration phenomenon occurs in rural 
labor force in China. So, the supply of rural labor force is insufficient. In fact, this is an inevitable result after marketization selection. Comparative income and marginal return gained in rural area are greatly below income gained in large and medium cities. Rational people will naturally select to leave rural area and work outside. Peasants will go to town and become peasant workers. In this way, rural surplus labor migration appears. Once marginal productivity is above zero, labor force will shift to the cities with high productivity from rural areas with low marginal productivity. In this way, total output in cities increases. However, this rise is at the cost of the decrease in gross output in rural area. In fact, labor service economy with wage income of migrant worker group as the most important form has become a main approach of peasant group income rise. Meanwhile, labor force is an important force for Chinese rural economic development. In China, agriculture industry has the features of feebleness and limitation. It is necessary to improve supply elasticity of labor force through migration of non-agricultural industries under the condition of small possibility in increasing peasants' income and thus become a main channel of peasants' income rise. Once rural productivity increases, return rate of rural labor force will surpass that brought by out-migration for work. Thus, reserve migration of labor force population will appear. In other words, outflow labor forces return to rural areas again. Then, the quality of rural labor force resources will improve. In this way, a final outcome is that other sectors and agricultural sector own the same marginal productivity. This marks dual economic structure is replaced by single economic structure.

\section{To construct employment market with urban-rural integration}

Currently, marketization degree of Chinese labor force is relatively low, and labor resource allocation among various regions, ownership enterprises, cities and rural areas are influenced by numerous non-price factors. Thus, marginal productivity difference of labor force resources is very large. Under current labor market where urban and rural areas tend to be unified, looser census register management system should be adopted. Urban registered permanent residence of counties and below need to continue to expand. Besides, all large and medium cities should actively create conditions and make numerous migrant workers to really settle down. In household registration system reform, the cost of surplus rural labor forces settling down in cities should decrease as far as possible so that they can be really liberated. Currently, it is very hard for peasants to gain permanent residency right in cities. Thus, large quantities of migrant workers return to hometown after accumulating certain wealth. Once peasant workers lack long-term and stable expected income, their savings will not form positive influence on national economic development. Similarly, this is not beneficial to cultivating and promoting skill quality of vast workers.

\section{To guide surplus rural labor force to shift to the tertiary industry}

Practical experience of western developed countries has proven that practical experience at the beginning of industrialization will rapidly spring up in industries and cities. However, at the end of industrialization, rural labor force should transfer to the tertiary industry. In accordance with short supply of rural labor force, urbanization and non-agriculturization should be considered at the same time to promote non-agriculturization transfer in rural areas. In many western developed countries, surplus labor force migration in rural areas showed population migration to cities from rural areas and urbanization level obviously improved as early as 1950s due to positive implementation of industrialization. However, after, this situation changed. Surplus rural labor force increasingly tended to transfer to rural areas rather than cities. Rural surplus labor forces mainly transfer internally. This is mainly reflected in urbanization of rural areas. In this way, urban-rural gap will further narrow. Generally, non-agriculturization and urbanization of western developed countries keep pace. Many developed countries will no longer have urban-rural differences.

\section{To improve cultural quality and skill quality of surplus rural labor force}

It is necessary to practically alter the education policy of valuing cities and ignoring rural areas, continuously increase rural basic education construction force and cultivate the next generation of rural labor force with high quality. In current stage, overall cultural level of China's rural labor force is low, and the proportion of rural labor force receiving vocational training is quite low. In line with Micha Gisser's researches, $10 \%$ rise in rural education level will cause that $6 \%-7 \%$ peasants break away from agriculture. Western countries pay much attention to culture and skill quality education of 
rural labor force during carrying out agricultural modernization. The government is responsible for appropriation to support development of education. At present, China should extend compulsory education for 3 years on the basis of nine-year compulsory education, i.e. increase three-year study in senior high school or increase three-year vocational education study. This badly needs the government to increase investment in rural education.

\section{To spare no effort to expand international labor market}

Seeing from development of socialist market economy with Chinese characteristics, marketization and industrialization of rural labor force are inevitable choices. Thus, to further improve organization degree of rural labor force output process, firstly, it is required to implement labor service output as an emerging industry and improve labor service output behaviors from multiple aspects (educational training, combination of supply and demand and employment security) in accordance with requirements of marketization, industrialization and standardization. Secondly, professional and series services should be adopted to accelerate labor service output process and achieve connection with market economy. At present, China's labor service output lags behind western developed countries and numerous developing countries. Therefore, the government should loosen relevant policies and expand international labor service market through multiple approaches. The proportion of agricultural population in total population is very large. Once life of mass peasants cannot be well solved, this will influence social harmony and stability. Currently, China's agriculture is transiting to modern agriculture from traditional agriculture. How to smoothly implement rural surplus labor force is very important. In general, China's rich labor resource superiority should be better utilized to attract foreign investment, increase corresponding posts and boost living standards of mass peasants.

\section{References}

[1] Liu Chengyu, On several problems of agriculture and rural labor transfer. Research of Agricultural Modernization, 2009 (6)

[2] Nie Hualin, Li Guangquan, Review of harmonious development of labor service economy and China's rural economy under financial crisis. Journal of Zhongnan University of Economics and Law, 2009 (6)

[3] Fu Boren, Study on rural labor transfer under financial crisis. Research of Agricultural Modernization, 2009 (6)

[4] Geng Lingling, Study on main problems faced by rural labor transfer and countermeasures. Industrial Economy, 2010 (21) 